\title{
Quantitative analysis of the steroidal calcitriol-mediated regulation of the serological components responsible for IDA and TSH disorders in reproductive and nonproductive women
}

\author{
Salauddin Al Azad', Sharmin Ahmed², Partha Biswas ${ }^{3}$, Md. Abdur Rashid Mia ${ }^{4}$, Mithila \\ Farjana $^{5}$, Farzana Alam Arshe ${ }^{6}$, Sabrina Jahan Mily ${ }^{7}$, Ananya Baidya Ankhi ${ }^{8}$, Mahdi \\ Mubin Shaikat", Sabeeha Sultana ${ }^{10}$, Kashfia Mawa ${ }^{11}$, Zannatul Naim ${ }^{12}$, Md. Ataur \\ Rahman $^{13,14,15^{*}}$, Bonglee Kim ${ }^{14,15^{*}}$
}

\footnotetext{
${ }^{1}$ School of Biotechnology, Jiangnan University, Wuxi, Jiangsu, 214122, PR China

${ }^{2}$ College of Public Health Sciences, Chulalongkorn University, Bangkok, 10330, Thailand

${ }^{3}$ Department of Genetic Engineering and Biotechnology, Jashore University of Science and Technology, Jashore, 7408, Bangladesh

${ }^{4}$ Department of Pharmaceutical Technology, Faculty of Pharmacy, International Islamic University Malaysia, Kuantan, 25200, Malaysia

${ }^{5}$ Department of Chemistry and Biochemistry, University of Oklahoma, Norman, 73019, USA

${ }^{6}$ Department of Biochemistry and Microbiology, North South University, Dhaka, 1229,

Bangladesh

${ }^{7}$ Ministry of Health, People's Republic of Bangladesh

${ }^{8}$ Department of Gastroenterology, Square Hospitals LTD, Dhaka, 1205, Bangladesh

${ }^{9}$ Department of Mathematics and Natural Sciences, School of Data and Sciences, BRAC

University, Dhaka, 1212, Bangladesh

${ }^{10}$ Enam Medical College and Hospital, Savar, Dhaka, 1340, Bangladesh

${ }^{11}$ Department Public Health \& Bioinformatics, Asian University for Women, Chittagong, 4000, Bangladesh

${ }^{12}$ Department of Animal Production and Management, Sher-e-Bangla Agricultural University, Dhaka, 1207, Bangladesh.

${ }^{13}$ Global Biotechnology \& Biomedical Research Network (GBBRN), Department of Biotechnology and Genetic Engineering, Faculty of Biological Sciences, Islamic University, Kushtia 7003, Bangladesh.

${ }^{14}$ Department of Pathology, College of Korean Medicine, Kyung Hee University, Seoul 02447, South Korea.

${ }^{15}$ Korean Medicine-Based Drug Repositioning Cancer Research Center, College of Korean Medicine, Kyung Hee University, Seoul 02447, Korea.
}

Correspondence:

Md. Ataur Rahman, Email: ataur1981rahman@hotmail.com

Bonglee Kim, Phone: E-mail: bongleekim@khu.ac.kr 


\begin{abstract}
Anemia and thyroid disorders are global health issues that affect all ages but are more apparent in women. In this case, some serological components responsible for IDA and TSH disorders in women have been found actively regulated through a complex steroidal-calcitriol mediated pathway. This research has been investigated the correlation between Calcitriol and the serological components responsible for IDA and TSH disorders in childbearing and non-childbearing women of different health conditions. Experimental sampling from 452 women suffering from both IDA and TSH disorders were taken, aged between 0 and 70 years. Serological parameters, such as iron, total iron-binding capacity and ferritin, were assessed for IDA profiling, whereas thyroid-stimulating hormone and free thyroxin were for TSH profiling based on the individual's serum calcitriol status. The resulted serological data were interpreted using sophisticated computer programming language and algorithms for quantitative biochemical analysis. The study resulted in a significant correlation between FT4 and Calcitriol $(\mathrm{P}<0.0001)$ for all age groups. TSH also showed strong interactions with the fluctuation of calcitriol level $(\mathrm{P}<0.0001)$, except for the children aged below 10 years $(\mathrm{P}<0.063)$. The iron, TIBC, TSH, and FT4 showed phenomenal regulation with the steroidal-calcitriol concentration for congenital patients. Unlike the others, ferritin has a substantial connection with Calcitriol $(\mathrm{P}<0.0064)$ fluctuation in the serum. To ratify, the concentrations of TSH, FT4, iron, TIBC, and ferritin were found to be significantly interconnected in terms of serum calcitriol level in women suffering from IDA and TSH disorders simultaneously. To understand the accuracy and efficacy of the Calcitriol in IDA and TSH disorders, some other inflammatory markers and parathyroid hormone analysis are need in future studies, besides a large number of samples.
\end{abstract}

Keywords: TSH disorder, IDA, TIBC, ferritin, FT4, Calcitriol mediated regulation, reproductive and non-reproductive women, quantitative serological assessment. 


\section{Introduction}

Anemia is a global public health concern nowadays that affects developing countries and developed countries with the major consequences of human health hazards. According to the previous data, it affects one-quarter of the global population, with pregnant women and young children having a higher prevalence rate than men [1]. Turning to the factors, iron deficiency is the major cause of poor nutrition, which correspondingly results in severe Anemia with the consequence of both mother and child's death [2]. Iron is vital to all biological functions, including DNA synthesis, respiration, cell proliferation, energy production, and so on [3]. Over 2 billion people are affected by iron deficiency worldwide [4, 5], and the ubiquity of Anemia among pregnant women and young children due to Iron depletion has been well documented [6, 7]. Age is also significantly correlated with IDA in females of childbearing and pregnancy [8]. Additionally, premenopausal women who stick to a restrictive diet and usually intake a little amount of iron are mostly at risk of iron deficiency since they also lost iron during their menstrual cycle; however, in 2002, WHO reported iron deficiency anemia (IDA) as one of the most important factors to the global burden of disease [9]. Therefore, frequent screening of IDA is very significant. Numerous iron indicators are used to screen for IDA, and a potential example is how serum ferritin can be used as a diagnostic tool in clinical practice [10]; a combination of two serum transferrin markers are used in detecting IDA in regular hemodialysis anemic patients [11].

Thyroid dysfunction is also one of the most prevalent endocrine disorders worldwide [12]. Globally about 1.6 billion people are at risk of developing thyroid disorder due to iodine deficiency [13]. There are two types of thyroid disorder means- hyperthyroidism and hypothyroidism. Iron status in humans is inextricably related to thyroid function. IDA deteriorates thyroid metabolism and retards the physical and mental development of both young and adult individuals. Based on several investigations, both ID and Anemia are interconnected with hypothyroidism which significantly increases serum TSH levels and decreases serum iron, serum ferritin, Free T4, transferrin, RBC count, and so on [14-18]. Ferritin is a universal protein that acts as an iron carrier, and serum ferritin level is negatively correlated with serum TSH levels $[19,20]$. In addition to iron and ferritin, Values of TIBC, FT3, and FT4 were significantly lower in hypothyroid patients suffering from IDA [21, 22]. This lower serum ferritin level is also 
associated with reducing sex hormones along with TSH, which exaggerates another endocrine dysfunction [23]. To summarize the inter-connection, on the one hand, deficiency of iron can produce hypothyroidism [24]. On the other hand, alterations in thyroid status change serum iron metabolism and hematological index [16].

Calcitriol is an activated form of vitamin D, which is semi-synthetic and hormonally active. Vitamin D is a fat-soluble steroid hormone mainly produced in the skin when exposed to sunlight. Vitamin D may also be acquired from the ingested diet to a minor extent [25]. To explain further, vitamin D biosynthesis in the skin becomes initiated by UV rays of sun lights which convert 7-dehydrocholesterol to pre-vitamin D3; then, it is thermally isomerized to vitamin D3. Calcitriol is the main vitamin D metabolite and is the best determiner of vitamin D nutritional status in the flow. However, this metabolite is not the active form of vitamin D, which requires a further activation step, and this happens in the presence of the catabolic enzyme 25OHD-1- $\alpha$-hydroxylase (CYP27B1) to finally generate Calcitriol (1,25-(OH)2D3) [26, 27]. In recent years, Calcitriol has taken close attention because its deficiency entails the risks of various human diseases such as gestation-associated disorders [28]. According to previous studies, Calcitriol (activated vitamin D) insufficiency affected over one billion people globally [29, 30]. The lower calcitriol levels are associated with higher serum TSH levels [25] and lower hemoglobin and ferritin levels [31]. Studies highly suggested the supplementation of vitamin D in case of hypothyroidism and Anemia, along with the high recommendation for the screening of the vitamin D deficiency in all hypothyroid patients [25, 32]. It is practically required for monitoring iron nutritional status as it exaggerates thyroid disorders in reproductive age and pregnant women [14]. Thyroid dysfunctions must also be considered by physicians treating Anemia to ensure early detection and proper treatment [33]. Based upon various factors like lifestyle, climatic conditions, sun exposure, and diet, vitamin D supplementation should be determined. Literature reveals that there is no study conducted yet on Bangladeshi patients suffering from iron deficiency anemia and thyroid deterioration, especially in women.

Considering all the aforementioned facts, this current study aims to evaluate the relationship between Calcitriol, IDA, and TSH disorders. At the same time, the serological significance of Calcitriol was determined in regulating both the iron contents and thyroid cycle of women of all ages simultaneously. In addition, a new dimension of diagnosing and studying the serological 
status of the anemic and thyroid patients depending on their calcitriol profiles can be achieved, through which it should be clinically suggestive as a steroidal biomarker for IDA and TSH disorders.

\section{Materials and methods}

\section{Clinical diagnosis}

The current research started with diagnosing serum calcitriol levels [34] of the 452 women suffering from IDA and TSH simultaneously, as suggested by their doctors and 6 healthy women, to be used as control. To analyze the regulatory effects of Calcitriol on the IDA and TSH disorders among the patients, several specific serological parameters were considered, such as serum iron $(\mu \mathrm{g} / \mathrm{dl})$, total iron-binding capacity (TIBC, $\mu \mathrm{g} / \mathrm{dl})$, and ferritin $(\mathrm{ng} / \mathrm{dl})$ for IDA confirmation. Whereas, serum thyroid-stimulating hormone (TSH, $\mu \mathrm{IU} / \mathrm{ml}$ ) and free thyroxine (FT4, ng/dl) were assessed to determine the TSH disorders. The iron ( $\mu \mathrm{g} / \mathrm{dl})$ and TIBC $(\mu \mathrm{g} / \mathrm{dl})$ level of the patients' serum were quantitatively analyzed using 'Dimension ${ }^{\circ} I R O N$ Flex ${ }^{\circledR}$ reagent cartridge (DF85)' and 'Dimension ${ }^{\circledR F l e x}{ }^{\circledR}$ Reagent IBCT' (Siemens Healthcare Diagnostics Inc., USA) respectively, following the referred methodology [35, 36]. The ferritin level (ng/dl) was tested quantitatively with 'Beckman Coulter Access Ferritin Calibrators (S0S5)' considering its established protocol $[36,37]$. On the other hand, 'ADVIA®Centaur'TM TSH3 Kit' (Siemens, USA) and 'ADVIA ${ }^{\circledR}$ Centaur'TM FT4 Kit' (Siemens, USA) were used to diagnose TSH ( $\mu \mathrm{IU} / \mathrm{ml})$ and FT4 (ng/dl) respectively. Different patient groups were classified following their age, reproductive status, and past clinical history in all aspects. All of those serum components were tested depending on their respective calcitriol level counts to identify if there were any precise correlation with Calcitriol or not. For transparent analysis, clinical data of the same serological tests and the calcitriol profiling of several normal women were also used as a control to compare with the IDA and TSH patients. The ethical clearance was officially taken from the Committee of Ethical Issues of JMC, Bangladesh Medical and Dental Council (BMDC), with the Principal's authorization and the Pathology Unit's Supervisor.

\section{Post-diagnostic quantitative assessment}

To study the quantitative interactivity of the aforementioned serum components based on the individuals' calcitriol level, different bioanalytical parameters were preferred, including- twoway ANOVA test, Brown-Forsythe test, Bartlett's test, and Tukey's multiple comparisons test 'p 
values,' as the primary factors. In addition, least-square mean (LSM), mean difference (MD); standard error of the difference (SED); the difference between predicted means (DBPM), and 95\% CI of difference (95\% CID) were analyzed as the secondary parameters. In this study, Calcitriol was assigned to be considered as a serological marker only if its quantitative values belong to $\mathrm{P}<0.02$ in all the primary and secondary parameters, to each of the selected serum components; so that the analysis can be more authentic as compared to the $\mathrm{P}<0.05$ scale [38].

\section{Software tools for data analysis and validation}

The biostatistical analysis and computational algorithms were performed using computational ' $R$ Programming Scripts' (version R-4.0.2, for Linux) [39, 40] and 'GraphPad Prism' (version 8.1.2, for Mac OS) [41, 42, 43] premium software packages.

\section{Results}

In this research, the concentrations of TSH, FT4, iron, TIBC, and ferritin level were found regulating with the concentrations of the serum calcitriol level of the corresponding women suffering from TSH and IDA disorders. Individuals patients belonging between 11 to 70 years possess a very strong correlation of both the TSH and FT4 level $(\mathrm{P}<0.0001)$ with their respective calcitriol counts (in the scale of significance $\mathrm{P}<0.02$ ) (Figure 1). Though there is an insignificant relationship between the TSH and calcitriol level $(\mathrm{P}<0.063)$ among the patients ranged between 0 to 10 years (Figure 1A), the correlation between FT4 and Calcitriol is highly significant $(\mathrm{P}<0.0001)$ for the same age group (Figure 1B). The upper and lower values of TSH and FT4 are- $3.1(\mu \mathrm{IU} / \mathrm{ml}), 1.2(\mu \mathrm{IU} / \mathrm{ml})$, and $1.25(\mathrm{ng} / \mathrm{dl}), 1.01(\mathrm{ng} / \mathrm{dl})$ respectively, for the women aged below 10 years. In both aspects, the calcitriol upper and lower values are- 25.3 (ng/ml) and 8.19 $(\mathrm{ng} / \mathrm{ml})$. 

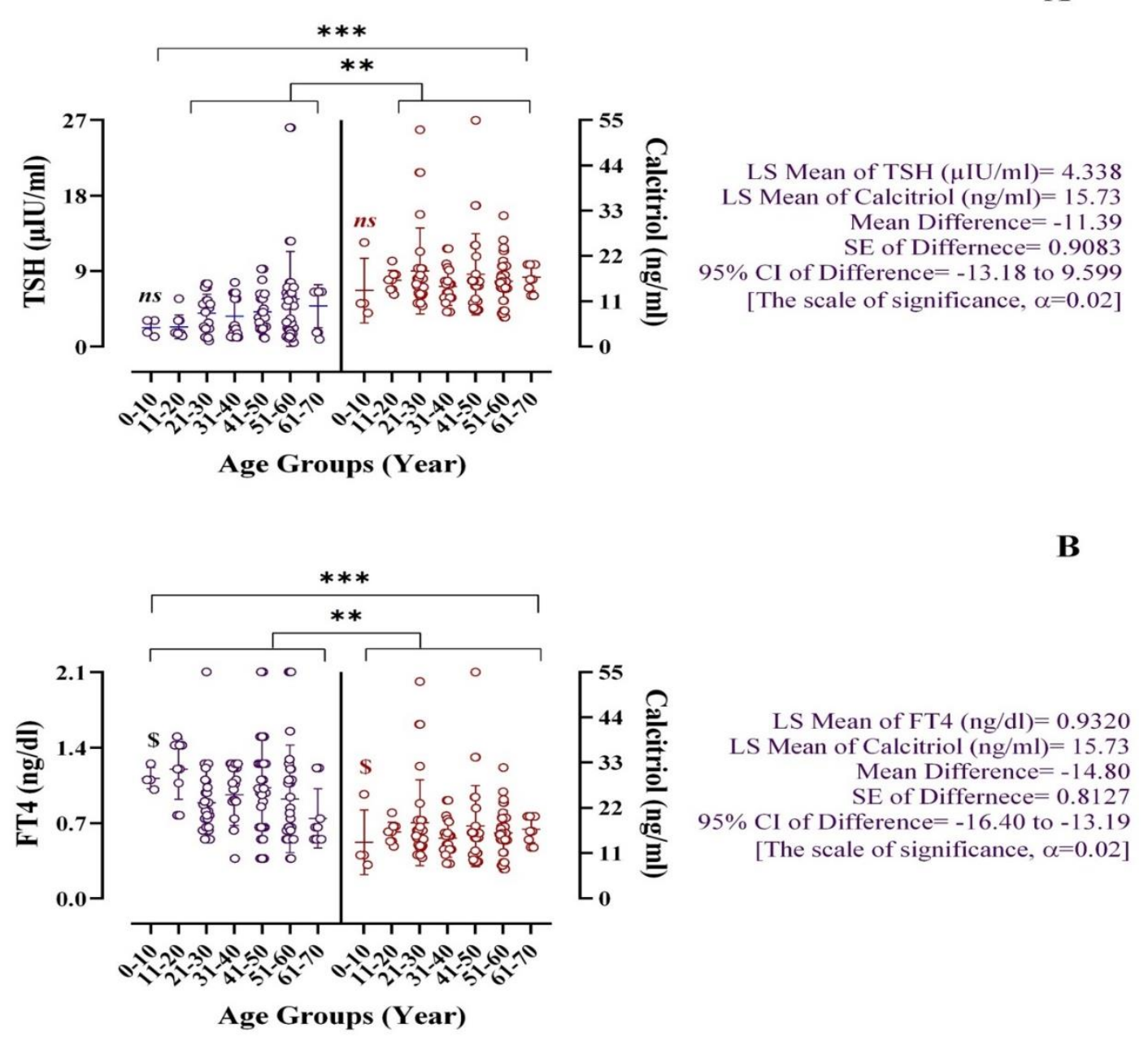

Figure 1: (A)-The correlation between the thyroid-stimulating hormone (TSH) and Calcitriol; (B)-The correlation between free thyroxin (FT4) and calcitriol status in thyroid disorder women patients. $\mu \mathrm{IU} / \mathrm{ml}$ (micrograms international units per millilitre), $\mathrm{ng} / \mathrm{mL}$ (nanograms per millilitre), LS mean (the mean of Longitudinal Section), SE (standard error), CI (confidence interval).

The serum iron, TIBC, and ferritin level fluctuate dramatically with the concentration of calcitriol present for all the selected patients from different age groups, resulted in the current serological quantitative analysis (Figure 2). The iron level increases $(150 \mu \mathrm{g} / \mathrm{dl})$ and decreases $(9 \mu \mathrm{g} / \mathrm{dl})$ with the increase and decrease of calcitriol level as $54.98 \mathrm{ng} / \mathrm{ml}$ and $8 \mathrm{ng} / \mathrm{ml}$, respectively. The correlation between iron and Calcitriol is found significant $(\mathrm{P}<0.0001)$ among 
A

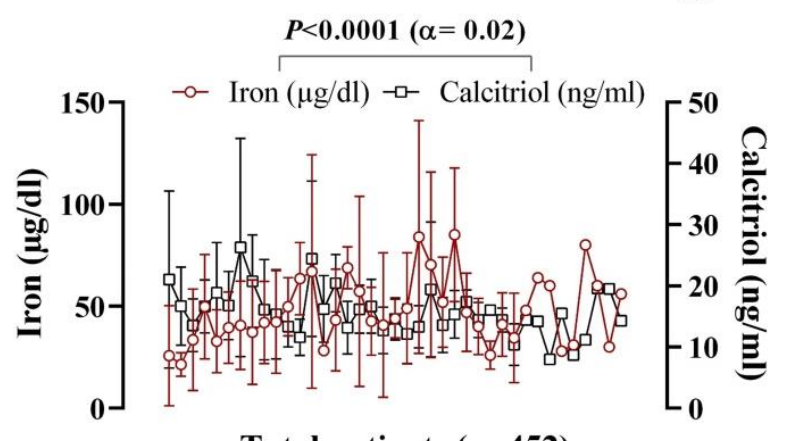

Total patients $(n=452)$
B

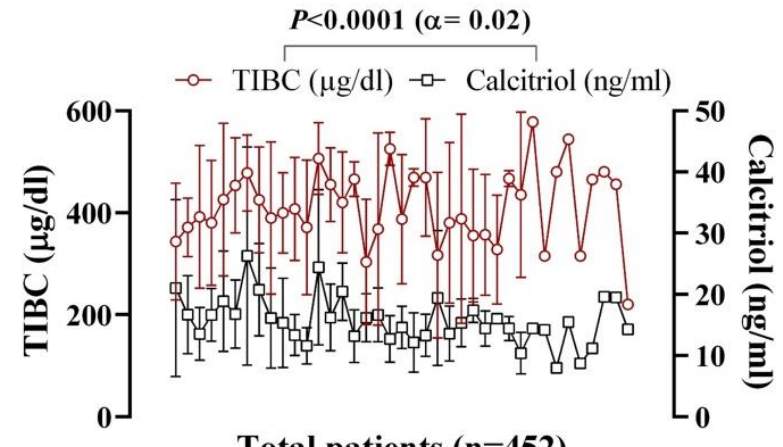

Total patients $(\mathrm{n}=\mathbf{4 5 2})$

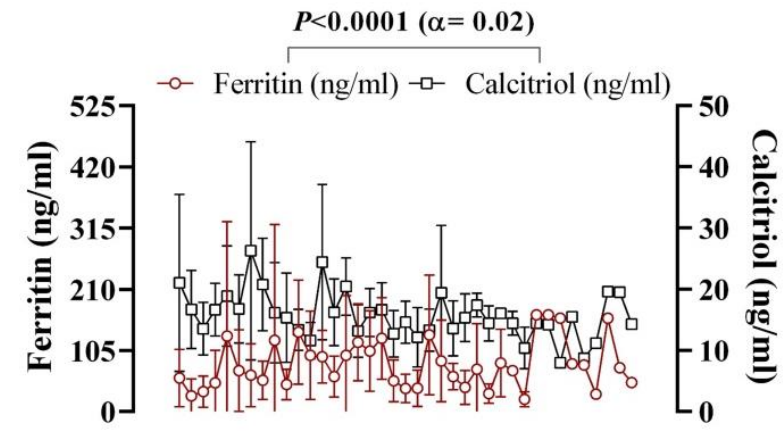

Total patients $(n=452)$

Figure 2: (A)-The correlation between iron and Calcitriol; (B)-The correlation between TIBC and Calcitriol; (C)The correlation between ferritin and calcitriol status in anemic women of reproductive ages. TIBC (total iron binding capacity), Calcitriol (activated vitamin D3), $\mu \mathrm{g} / \mathrm{dL}$ (micrograms per deciliter), $\mathrm{ng} / \mathrm{mL}$ (nanograms per milliliter).

The reproductive patients (Figure 2A). On the other hand, TIBC increased $(580 \mu \mathrm{g} / \mathrm{dl})$ with the reduction of Calcitriol $(8 \mathrm{ng} / \mathrm{ml})$ and decreased $(156 \mu \mathrm{g} / \mathrm{dl})$ with the progress of calcitriol concentration $(52.7 \mathrm{ng} / \mathrm{ml})$, means their serological profiles are reversible to each other (Figure 2B). Similarly, ferritin downregulates $(5 \mathrm{ng} / \mathrm{ml})$ as the calcitriol level promotes $(52.7 \mathrm{ng} / \mathrm{ml})$, resembling the findings of TIBC as well (Figure 2C) among the reproductive women. In both the cases of TIBC and ferritin, the values are equally significant $(\mathrm{P}<0.0001)$ when correlated with their calcitriol limits (Figure 2B and C). The correlation of iron, TIBC, and ferritin in respect to the calcitriol level has also been found significant to the nonproductive women $(\mathrm{P}<0.0001$ for each in the scale of significance $\mathrm{P}<0.02)$, except the women aged below fourteen years. 
This study experienced 13 congenital cases of IDA and TSH disorders among all women. Surprisingly, according to their calcitriol profiles, all serological parameters have been found highly significant considering their two-way ANOVA and 'Tukey's multiple t-tests' of variables (Figure 3). For the congenital patients, individual correlations of TIBC, TSH, and FT4 with their calcitriol concentration is exactly $\mathrm{P}<0.0001$ (Figure 3A).

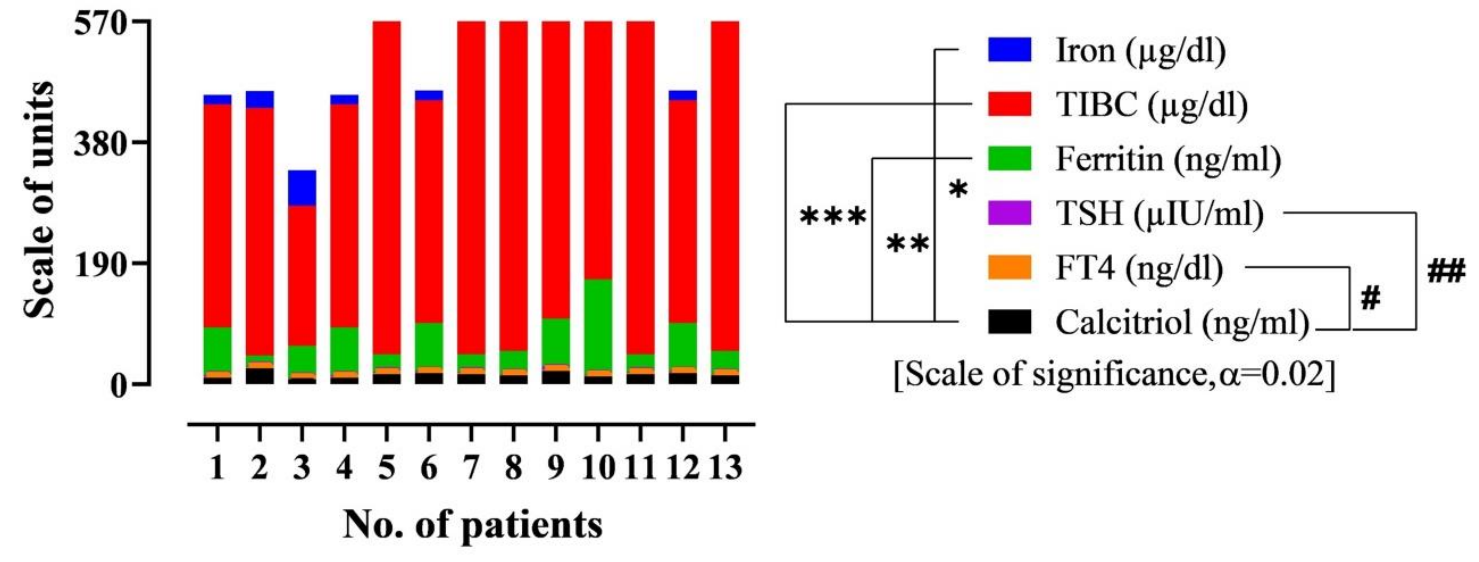

B

\begin{tabular}{cccc}
\hline \multicolumn{4}{c}{ Level of divergence } \\
\hline Interactives & DBPM & SED & 95\% CID \\
Calcitriol - TSH & -13.00 & 1.215 & -15.64 to -10.35 \\
Calcitriol - FT4 & -14.16 & 1.250 & -16.88 to -11.44 \\
Calcitriol - Iron & 18.13 & 6.690 & 3.552 to 32.71 \\
Calcitriol - TIBC & 440.1 & 33.62 & 366.9 to 513.4 \\
Calcitriol - Ferritin & 42.21 & 10.38 & 19.60 to 64.81 \\
\hline
\end{tabular}

Figure 3: (A)-Two-way ANOVA and 'Tukey's multiple t-tests' showing the correlation of the variables with Calcitriol among 13 congenital cases of IDA and TSH disorder. The stacked columns demonstrate the relationship of Iron, TIBC, Ferritin, TSH, and FT4 against Calcitriol in the case of 13 congenital patients who had Iron Deficiency Anemia and Thyroid Deficiency. (B)- Level of divergence of the obtained values from Fig 3A has 95\% confidence considering the DBPM, SED, CID parameters. TIBC (Total iron-binding capacity), TSH (Thyroidstimulating hormone), FT4 (Free thyroxine), Calcitriol (Activated vitamin D3), * and \# (Level of significance).

In contrast, ferritin shows a strong correlation but unlike the others with Calcitriol, means $(\mathrm{P}<0.0064)$. The values obtained from the interactive components means iron, TIBC, ferritin, TSH, and FT4, with the Calcitriol, have been found very authentic considering their DBPM, SEM, and CID parameters, which established the findings as 95\% confident (Figure 3B). It's 
resulted that there is no null (' 0 ') values in their 95\% CID, which means the quantitative outputs are highly authentic and statistically significant. The ' $\mathrm{Z}$ value' for $95 \%$ confidence is 1.96 $(\mathrm{Z}=1.96)$ as calculated from the statistical parameters (Figure 3).

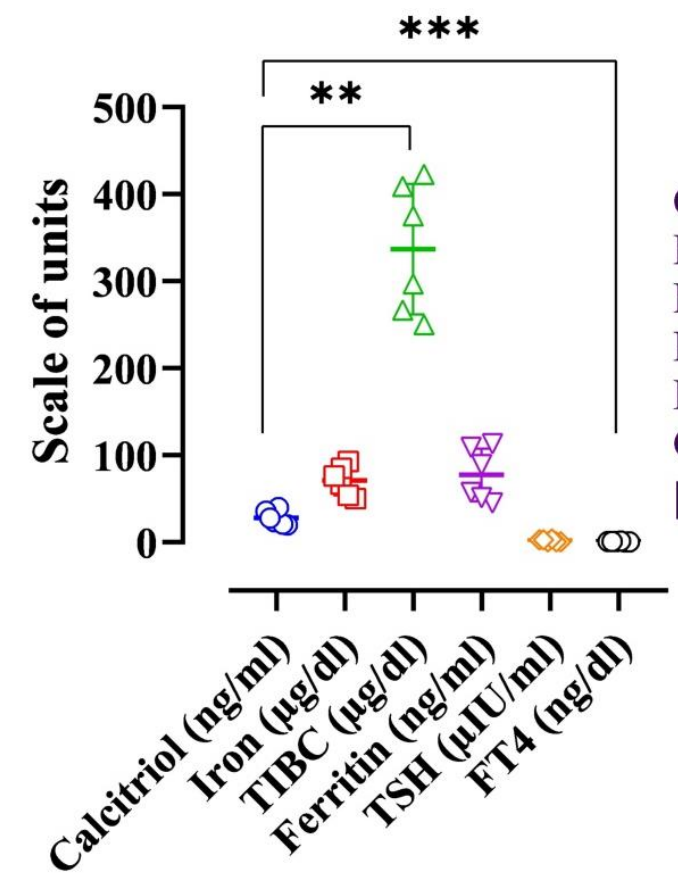

Overall One-way ANOVA Test $\mathrm{P}$ value is $<0.0001$ $\mathrm{R}$ square $=0.9337$

Brown-Forsythe test $\mathrm{P}$ value is $<0.0001$

Bartlett's test $\mathrm{P}$ value is $<0.0001$

Bartlett's statistics $($ Corrected $)=84.97 \%$

Calcitriol and TIBC correlation $(\mathrm{P}<0.0001)$

[Scale of significance, $\alpha=0.02$ ]

Figure 4: Figure: Level of Calcitriol, Iron, TIBC, Ferritin, TSH, and FT4 of six normal women and the potential relationship between calcitriol level and value of the other five serological parameters Graph. TIBC-Total Ironbinding capacity, TSH-Thyroid stimulating hormone, FT4-Free thyroxine.

The overall results of each parameter were assessed based on the standard data generated by sampling the same serological parameters from six normal women as a control to compare their calcitriol status with the diseased women. The calcitriol level of the normal women ranged between $20 \mathrm{ng} / \mathrm{ml}$ to $40 \mathrm{ng} / \mathrm{ml}$. In response to which, their iron, TIBC, ferritin, TSH and FT4 ranges found as 50-93 $\mu \mathrm{g} / \mathrm{dl}, 250-423 \mu \mathrm{g} / \mathrm{dl}, 45-113 \mathrm{ng} / \mathrm{ml}, 0.5-4.0 \mu \mathrm{IU} / \mathrm{ml}$, and 0.70-1.67 ng/dl respectively (Figure 4). 


\section{Discussion}

The term "vitamin D" refers to a group of secosteroid compounds, two of which, cholecalciferol (known as vitamin D3) and ergocalciferol (also known as vitamin D2), are most commonly associated with the term [44]. The former is composed of a reduction of 7 dehydrocholesterol in the skin following the exposure to ultraviolet B (UVB) radiation from few dietary sources (mainly fish fat). At the same time, the latter is compounded by plants and fungi, which can form a dietary basis of vitamin D2 for people [45]. Both D2 and D3 are hydrolyzed with 25hydroxyvitamin D $(25(\mathrm{OH}) \mathrm{D}$, calcidiol), the principal form of vitamin D circulation and storing in the liver [46]. The active hormone is formed when $25(\mathrm{OH}) \mathrm{D}$ is hydroxylated to $1,25-$ dihydroxyvitamin $\mathrm{D}(1,25(\mathrm{OH}) 2 \mathrm{D}$, Calcitriol). This transformation usually occurs in the kidney and is governed by negative responses due to high Calcitriol and fibroblast growth factor 23 (FGF23) [46]. Calcitriol attaches to the intracellular vitamin D receptor (VDR) that influences the response components of objective genes [47].

Calcitriol has long been recognized as an important hormone in regulating the musculoskeletal system, and it continues to be so today. The extra-skeletal effects of 1,25(OH)2D were also highly researched over the last decade after the presence of vitamin D receptors in almost all tissue types was established [48]. In the context of thyroid disorders, the antiproliferative and differentiating effects of Calcitriol are significant, and its function in modulating the immune system has been demonstrated in autoimmune thyroid disease (AITD) [27, 44]. Several research studies have shown that vitamin D3 has vital roles in maintaining bone health, immunity, and muscles. Several studies showed a link between vitamin D deficiency and thyroid disorders [49]. IDA is a common problem and highly prevalent among Bangladeshi women, especially among pregnant women and females living in low iron water supplies [50]. Many IDA patients remain undiagnosed worldwide as the early stages show minor symptoms.

Furthermore, people with chronic diseases like CVD (cardiovascular diseases) and CKD (chronic kidney diseases) have more significant risks of suffering from IDA [51]. The function of several proteins, metabolic activity, including imbalance of thyroid hormones, may occur due to iron deficiency. Changes in ferritin levels affect thyroid functions. Low levels of TSH and high levels of FT4 occur due to an imbalance in TSI (thyroid-stimulating immunoglobulin), leading to 
hyperthyroidism. FT4 does not bind to proteins, which is good for diagnosing thyroid problems [52].

The potential relationship of activated vitamin D3 (Calcitriol) with the regulation of thyroidstimulating hormone (TSH) has been identified (Figure 1A). We have collected the TSH in $\mu$ IU unit and Calcitriol in $\mathrm{ng} / \mathrm{ml}$ unit of serum concentration from 452 women blood who possessed the TSH and IDA disorders according to the age limit of 0 to 70 . According to the current study, the age limit was conducted among the 10 years intervals for the higher frequency of random sample collection. After the statistical analysis of the relationship of TSH and Calcitriol, it showed $(\mathrm{P}<0.063)$ among the patients ranged between 0 to 10 years. The values of the serological components for the women beneath 10 years can act randomly because their hormonal and metabolic profile remained developmental like the neonatal, which can fluctuate insignificantly under any circumstances [53]. According to the result of figure 1 (A), the LS mean of TSH and Calcitriol is 4.338 and 15.73, in which the Mean Difference and SE of Difference are -11.39 and 0.9083 .

This study analyzed Free T4 (FT4) measurements that are not bound and can freely enter and affect the body tissues. FT4 normal values are 0.7 to $1.9 \mathrm{ng} / \mathrm{dL}$ (Figure 4). Calcitriol can exert biological effects by binding with VDR (vitamin D receptor). Enzyme 1-alpha-hydroxylase (CYP27B1) catalyzes the calcidiol to Calcitriol and 24-hydroxylase (CYP24A1), Calcitriol inactivating enzyme, are crucial in governing the availability of active vitamin D. The effects of Calcitriol depend on VDR. Their polymorphic variants have been studied to a limited extent in the case of thyroid cancer [54]. In another study, there is an evaluation of the relationship between hypothyroidism and vitamin $\mathrm{D}$, and their results indicated that patients with hypothyroidism suffered from hypovitaminosis D with hypocalcemia [32]. A potential relationship has been obtained between activated vitamin D3 (Calcitriol) and FT4 (Figure 1B). The statistical analysis significant relationship of Calcitriol mediated FT4 regulation $(\mathrm{P}<0.0001)$ among the patients ranged between 0 to 10 years. The upper and lower values of FT4 and Calcitriol are 1.25 (ng/dl), 1.01 (ng/dl) and $25.3(\mathrm{ng} / \mathrm{ml}), 8.19(\mathrm{ng} / \mathrm{ml})$, respectively; where the LS means of FT4 and Calcitriol are 0.9320 and 15.73, in which the Mean Difference and SE of Difference are -14.80 and 0.8127 . 
Iron-deficiency anemia is defined when blood levels of iron will be low, or less than 10 micromoles per liter (mmol/L) for both men and women (normally 10-30 mmol/L) (Figure 4). Iron deficiency anemia increases susceptibility to infectious disease, increased child mortality, slowed child development, and reduced scholastic performance [55]. There is an association of calcitriol deficiency with the regulation of greater risk of Anemia, lower mean hemoglobin (LMH), and higher usage of erythrocyte-stimulating agents [56]. The research results have been depicted a strong correlation between iron and Calcitriol $(\mathrm{P}<0.0001)$ among the patients (Figure 2A). The calcitriol level of the normal women ranged between $20 \mathrm{ng} / \mathrm{ml}$ to $40 \mathrm{ng} / \mathrm{ml}$, and iron level is $50-93 \mu \mathrm{g} / \mathrm{dl}$ (Figure 4). Here Iron level is increased $(150 \mu \mathrm{g} / \mathrm{dl})$ and decreased $(9 \mu \mathrm{g} / \mathrm{dl})$ with the increase and decrease of calcitriol level as $54.98 \mathrm{ng} / \mathrm{ml}$ and $8 \mathrm{ng} / \mathrm{ml}$, respectively. Total iron-binding capacity (TIBC) plays a pivotal role in indirectly measuring the percentage of transferrin situation involved in positive correlation with vitamin D [57]. Transferrin and vitamin D levels decreased, whereas TIBC levels increased during iron-deficient anemic patients [58]. According to this study, the serum TIBC range for all the patients was between $220 \mu \mathrm{g} / \mathrm{dL}$ to 578 $\mu \mathrm{g} / \mathrm{dL}$ with some fluctuations.

In contrast, the activated Vitamin D (Calcitriol) value was between $8 \mathrm{ng} / \mathrm{mL}$ and $26.29 \mathrm{ng} / \mathrm{mL}$ with a little bit of oscillation. In this research, it was found that serum TIBC result was increased. In contrast, serum calcitriol level was decreased from all the individual patients, consequently indicating iron deficiency anemia [59], as compared to the normal range (Figure 4). The ferritin level in the human body indicates the iron status and iron storage. Ferritin levels are lower in people who have iron deficiency anemia, but they may be higher in people with inflammation and chronic disease-related Anemia [60]. However, in the present analysis, the range of the ferritin level was from $21 \mathrm{ng} / \mathrm{mL}$ to $166 \mathrm{ng} / \mathrm{mL}$ with some fluctuations, and calcitriol level was between the ranges of 8 to $26.29 \mathrm{ng} / \mathrm{mL}$ respected to the normal control. It was noticed that serum calcitriol value was slightly higher, whereas serum ferritin values were significantly lower following the calcitriol scores for all the patients (Figure 2C). The current investigation found a positive association between serum calcitriol and ferritin levels, consistent with previous findings $[61,62]$.

It is mainly due to maternal risk factors such as inadequate dietary intake of vitamin D, insufficient exposure to sunlight, and pregnancy that occurs close to the people who suffer from 
congenital calcitriol deficiency [63]. Low maternal vitamin D levels may raise the risk of a newborn's deficiency [64]. Besides, spontaneous hypothyroidism affects between $1 \%$ and $2 \%$ of the population and is more prevalent in older women [65]. Therefore, a poor pregnancy outcome is associated with vitamin D deficiency or insufficiency, which leads to several disorders such as low birth weight of newborns [66]. According to the current serological assessment, the value of Calcitriol (8.19-25.3ng/ml) and iron $(15-75 \mu \mathrm{g} / \mathrm{dl})$ reduced significantly (Figures 3A and 3B) than the control group (20-40 $\mathrm{ng} / \mathrm{ml})$ and (50-93 $\mu \mathrm{g} / \mathrm{dl})$, respectively (Figure 4). Moreover, the FT4 level decreased slightly from the control 0.7-1.67 ng/dl to congenital 0.77-1.5 ng/dl. On the other hand, TIBC, Ferritin and, TSH indicate an upper range of 220-566 $\mu \mathrm{g} / \mathrm{dl}, 17-150 \mathrm{ng} / \mathrm{ml}$, and, $1.2-5.7 \mu \mathrm{IU} / \mathrm{ml}$ than the healthy people $250-423 \mu \mathrm{g} / \mathrm{dl}, 45-113 \mathrm{ng} / \mathrm{ml}$, and, $0.5-4 \mu \mathrm{IU} / \mathrm{ml}$, respectively. The results possessed a higher percentage of TIBC and a lower percentage of TSH. The TIBC, TSH, and FT4 have a significant relationship with their calcitriol concentration which is exactly $\mathrm{P}<0.0001$, whereas the ferritin shows a strong correlation with Calcitriol $(\mathrm{P}<0.0064)$ (Figure 3A and 3B).

The research has described the values and regulatory relationships of the same serological parameters like iron, TIBC, ferritin, TSH, and FT4, with the Calcitriol of six normal women as a control group, where the range calcitriol level from the control group was found $20 \mathrm{ng} / \mathrm{ml}-40$ ng/ml, which was within the normal limit (Figure 4). On the other hand, the range of iron, TIBC, Ferritin, TSH, and FT4 were found 50-93mcg/dl, 250-423mcg/dl, 45-113n/ml, 0.5-4.0 mcgIUml, respectively, which were also within the normal ranges (Figure 4). The potential calcitriol-based regulation of the other serological parameters has been found in normal six women, used as the standard. Considering the biostatistical analysis, the overall one-way ANOVA test, BrownForsythe test, Barlett's test, and Calcitriol, a TIBC correlation P-value were all exactly $<0.0001$ (in the scale of significance $\mathrm{P}<0.02)$. The $\mathrm{R}$ square $\left(\mathrm{R}^{2}\right)$ value was 0.9337 , and Barrett's statistics was $84.97 \%$.

There are a lot of variables that were selected based on the inclusion and exclusion criteria. First of all, one of the study's advantages is that the samples were collected from about 452 individual patients and analyzed with automation equipment by skilled persons. The second is that volunteers with other diseases that could induce Anemia, such as Anemia due to inflammation or cause by genetic factors (i.e., thalassemia or sickle cell disease), were all eliminated. Therefore, activated vitamin D insufficiency is connected to Anemia and iron deficiency. Calcitriol 
promotes erythropoiesis, which may help to prevent Anemia. As a result, all patients diagnosed with vitamin D deficiency in the outpatient hospital should be tested for iron deficiency and Anemia. Those who require replacement medication should be provided it. However, Future studies are needed to determine the accuracy and efficacy of Calcitriol in IDA and TSH disorders, in addition to larger samples, biochemicals, inflammation markers, and parathyroid hormone analysis.

\section{Conclusion}

It is reasonable to expect that significant calcitriol (activated form of vitamin D) deficiency will occur in the majority of the women suffering from various forms of thyroid autoimmunity and iron deficiency anemia (IDA), based on our previous experience the findings of our research study. The question remains on how to respond in such a circumstance. Based on the results of our serological research study, it can be concluded that the concentrations of TSH, FT4, iron, TIBC, and ferritin were correlated with the levels of serum calcitriol or activated vitamin D3 in women suffering from TSH and IDA abnormalities. Moreover, depending on a woman's reproductive status and age, Calcitriol has been validated as a biomarker for tracking the status of IDA and TSH irregularities. However, more research with larger sample size is required to understand better the serological profiles of patients with IDA and TSH disorders.

\footnotetext{
Abbreviations

AITD-autoimmune thyroid disease, ANOVA-Analysis of Variance, BMDC-Bangladesh Medical and Dental Council, CID-Confidence Interval of difference, CKD -Chronic Kidney Diseases, CRP-C-Reactive Protein, CVD -Cardiovascular diseases, DNA- Deoxyribonucleic Acid, DBPMDifference between predicted means, FT3- Free Triiodothyronine, FT4- Free Thyroxine, IDAIron Deficiency Anemia, LSM-least-square mean, LMH-Lower Mean Hemoglobin, RBC- Red Blood Cell, MD- mean difference, SED-standard error of the difference, SEM-Standard Error of Measurement, TIBC- Total Iron Binding Capacity, TSH- Thyroid Stimulating Hormone, TSI Thyroid-stimulating immunoglobulin, UV-B-Ultraviolet B, VDR-vitamin D receptor, WHOWorld Health Organization.
} 


\section{Acknowledgments}

The authors are grateful to the RPG (Govt. License ID: 05-060-06021) for providing all types of unconditional supports in the technical issues (under the Project of Category: C2; ID. \#102021/22). At the same time, the authors are showing their gratitude to Dr. Faysal Al Mazid (KIST Scholar, South Korea) and Mr. Parag Kumar Paul (Dept. of Electrical and Electronic Engineering, United International University, Bangladesh) for supporting in final plagiarism and grammatical checking.

\section{CRediT Authors' contribution}

Conceptualization, Methodology, Supervision: Sharmin Ahmed; Project administration and Co-supervision: Salauddin Al Azad; Resources: Md. Abdul Rashid Mia, Data curation: Partha Biswas, Mithila Farjana; Writing original draft: All the authors participated equally; Visualization: Farzana Alam Arshe, Investigation: Sabrina Jahan Mily, Ananya Baidya Ankhi, Mahdi Mubin Shaikat; Validation and software: Salauddin Al Azad, Sabeeha Sultana, Kashfia Mawa, Zannatul Naim. Revision: Md. Ataur Rahman. Funding: Bonglee Kim.

\section{Research ethics}

The total research work was conducted under the Ethical Guidelines and Monitoring of Jashore Medical College (JMC), Bangladesh Medical and Dental Council (BMDC) in collaboration with the RPG Authority (Govt. Registration ID: 05-060-06021) under the Project Category C2 (\#Project EA No- 10/2021-2022). The Ethical Clearance have been approved by Prof. Dr. Md. Mohidur Rahman (Principal, JMC, Bangladesh), Dr. Md. Azam Saklain (Associate Prof. and Head of the Pathology Department, JMC, Bangladesh) and Dr. Sharmin Ahmed Shawon (Senior Lecturer, Pharmacology Department, JMC, Bangladesh; \& Researcher of 'College of Public Health Sciences, Chulalongkorn University', Bangkok, Thailand). Dr. Sharmin Ahmed Shawon $\left(\mathrm{BCS} 33^{\mathrm{rd}}\right)$ is the Supervisor of this research.

Funding: This research was supported by Basic Science Research Program through the National Research Foundation of Korea (NRF) funded by the Ministry of Education (NRF2020R1I1A2066868), the National Research Foundation of Korea (NRF) grant funded by the Korea government (MSIT) (No. 2020R1A5A2019413). 


\section{Conflict of interest}

The authors' have no competing interest at all with the others.

\section{Consent for publication}

The authors are very cordial in publishing the manuscript and their consent is clear. 


\section{References:}

[1] Bieri JGJTJoN. Second report of the ad hoc committee on standards for nutritional studies. J Nutr. 1980; 110:1726. doi: 10.1093/jn/110.8.1726.

[2] Macgregor MWJSMJ. Maternal Anemia as a factor in prematurity and perinatal mortality. Scot Med J. 1963;8:134-40. doi: 10.1177/003693306300800402.

[3] Hentze MW, Muckenthaler MU, Galy B, Camaschella C. Two to tango: regulation of Mammalian iron metabolism. Cell. 2010;142:24-38. doi: 10.1016/j.cell.2010.06.028.

[4] McLean E, Cogswell M, Egli I, Wojdyla D, de Benoist B. Worldwide prevalence of anaemia, WHO Vitamin and Mineral Nutrition Information System, 1993-2005. Public Health Nutr. 2009;12: 444-54. doi:10.1017/S1368980008002401.

[5] Kassebaum NJ, Jasrasaria R, Naghavi M, Wulf SK, Johns N, Lozano R, et al. A systematic analysis of global anemia burden from 1990 to 2010. Blood. 2014; 123:615-24. doi: 10.1182/blood-2013-06-508325.

[6] Gomes da Costa A, Vargas S, Clode N, L MG. Prevalence and Risk Factors for Iron Deficiency Anemia and Iron Depletion During Pregnancy: A Prospective Study. Acta Med Port. 2016; 29:514-8. doi: 10.20344/amp.6808.

[7] Gupta PM, Perrine CG, Mei Z, Scanlon KS. Iron, Anemia, and Iron Deficiency Anemia among Young Children in the United States. Nutrients. 2016;8. doi: 10.3390/nu8060330.

[8] Levi M, Simonetti M, Marconi E, Brignoli O, Cancian M, Masotti A, et al. Gender differences in determinants of iron-deficiency anemia: a population-based study conducted in four European countries. Annal Hematol. 2019;98:1573-82. doi: 10.1007/s00277-019-03707-w.

[9] Organization WH. The world health report 2002: reducing risks, promoting healthy life: World Health Organization; 2002.

[10] Khan A, Khan WM, Ayub M, Humayun M, Haroon M. Ferritin Is a Marker of Inflammation rather than Iron Deficiency in Overweight and Obese People. J Obes. 2016; 2016. doi: 10.1155/2016/1937320.

[11] Suega K, Kandarini Y, Tubung J. Role of Soluble Transferrin Receptor and Transferrin ReceptorFerritin Index to Detect Iron Deficiency Anemia in Regular Hemodialysis Patients. Open access Maced J Med Sci. 2019; 7:97-102. doi: 10.3889/oamjms.2019.012.

[12] Unnikrishnan AG, Menon UV. Thyroid disorders in India: An epidemiological perspective. Indian J Endocrinol Metab. 2011;15:S78-81. doi: 10.4103/2230-8210.83329.

[13] Ansari MAJJJoDMC. Thyroid disorders in Bangladesh-past, present and future. J Dhaka Med Coll. 2014; 23:151-2. doi: 10.3329/jdmc.v23i2.25323.

[14] Luo J, Wang X, Yuan L, Guo L. Iron Deficiency, a Risk Factor of Thyroid Disorders in Reproductive-Age and Pregnant Women: A Systematic Review and Meta-Analysis. Front Endocrinol. 2021; 12: 93. doi: 10.3389/fendo.2021.629831. 
[15] Refaat B. Prevalence and characteristics of Anemia associated with thyroid disorders in non-pregnant Saudi women during the childbearing age: A cross-sectional study. Biomed J. 2015;3 8:307-16. doi: 10.4103/2319-4170.151032.

[16] Rostaei Rad N, Vakili M, Zavar-reza J, Rezaie S, Shirvani ARJIJoML. The relationship between thyroid hormone levels and body iron status in iranian hypothyroidism patients. International Journal of Medical Laboratory. 2016;3:176-84.

[17] Sehat R, Shahabi Satlsar E, Hanachi PJJoPS. Association between Iron, TIBC and Ferritin with Thyroid Hormones Levels in Patients Referred to Shouride Clinic Laboratory. Journal of Payavard Salamat. 2019; 13:134-41.

[18] Khatiwada S, Gelal B, Baral N, Lamsal M. Association between iron status and thyroid function in Nepalese children. Thyroid Res. 2016; 9:2. doi: 10.1186/s13044-016-0031-0.

[19] Zilani MNH, Uddin SJ, Hossain H, Hazni H, Shilpi JA, Hossain MGJOP, et al. Chemical characterization and bioactivity of Trichosanthes dioica edible shoot extract. Orient Pharm Exp Med. 2018;18:167-75. doi: 10.1007/s13596-018-0310-5.

[20] He L, Shen C, Zhang Y, Chen Z, Ding H, Liu J, et al. Evaluation of serum ferritin and thyroid function in the second trimester of pregnancy. Endocr J. 2018;65:75-82. doi: 10.1507/endocrj.EJ17-0253. [21] Shukla A, Agarwal S, Gupta A, Sarkar GJNJoLM. Relationship between body Iron status and Thyroid profile in an adult population: A hospital based study. Natl. Lab. Med. 2017;6: B001-3. doi: 10.7860/NJLM/2017/24065:2204.

[22] El-Masry H, Hamed AM, Hassan MH, FAyEd HM, Abdelzaher MJJoC, Research D. Thyroid Function among Children with Iron Deficiency Anaemia: Pre and Post Iron Replacement Therapy. J Clin Diagnostic Res. 2018;12. doi: 10.7860/JCDR/2018/32762.11023.

[23] Mostafa GG, Zahran FE, Omer SA, Ibrahim A, Elhakeem H. The Effect of Serum Ferritin Level on Gonadal, Prolactin, Thyroid Hormones, and Thyroid Stimulating Hormone in Adult Males with Sickle Cell Anemia. J Blood Med. 2020;11:27-32. doi: 10.2147/JBM.S232562.

[24] Dahiya K, Verma M, Dhankhar R, Ghalaut VS, Ghalaut P, Sachdeva A, et al. Thyroid profile and iron metabolism: mutual relationship in hypothyroidism. Biomed Res. 2016;27.

[25] Beshboosh NN, Abd Alaali ZF, Mohammed MH. Relationship between vitamin d deficiency and physiological blood parameters in hypothyroidism patients. Biochem Cell Arch.18:465 - 70.

[26] Bikle D. Highlights from the 16th Vitamin D Workshop, San Francisco, CA, June 11-14, 2013. J Steroid Biochem Mol Biol. 2014;144 Pt A:1-4. doi: 10.1016/j.jsbmb.2014.04.016.

[27] Wacker M, Holick MF. Sunlight and Vitamin D: A global perspective for health. Dermatoendocrinology. 2013;5:51-108. doi: org/10.4161/derm.24494. 
[28] Olmos-Ortiz A, Avila E, Durand-Carbajal M, Díaz L. Regulation of calcitriol biosynthesis and activity: focus on gestational vitamin D deficiency and adverse pregnancy outcomes. Nutrients. 2015;7:443-80. doi: 10.3390/nu7010443.

[29] Nair R, Maseeh A. Vitamin D: The "sunshine" vitamin. J pharmacol Pharmacother. 2012;3:118-26. doi: 10.4103/0976-500X.95506.

[30] Holick MF, Chen TCJTAjocn. Vitamin D deficiency: a worldwide problem with health consequences. A J Clin Nutr. 2008;87:1080S-6S. doi: 10.1093/ajen/87.4.1080S.

[31] Anwar E, Farhana NJJoYP. Formulation and Evaluation of Phytosome-Loaded Maltodextrin-Gum Arabic Microsphere System for Delivery of Camellia sinensis Extract. J Young Pharm. 2018;10. doi: 10.5530/jyp.2018.2s.11.

[32] Mackawy AM, Al-Ayed BM, Al-Rashidi BM. Vitamin d deficiency and its association with thyroid disease. Int J Health Sci. 2013;7:267-75. doi: 10.12816/0006054.

[33] Soliman AT, De Sanctis V, Yassin M, Wagdy M, Soliman N. Chronic anemia and thyroid function. Acta biomed. 2017;88:119-27. doi: 10.23750/abm.v88i1.6048.

[34] Garabédian M, Jacqz E, Guillozo H, Grimberg R, Guillot M, Gagnadoux MF, Broyer M, Lenoir G, Balsan S. Elevated plasma 1,25-dihydroxyvitamin D concentrations in infants with hypercalcemia and an elfin facies. N Engl J Med. 1985 Apr 11;312(15):948-52. doi: 10.1056/NEJM198504113121503.

[35] Yamanishi H, Iyama S, Yamaguchi Y, Kanakura Y, Iwatani Y. Modification of fully automated total iron-binding capacity (TIBC) assay in serum and comparison with dimension TIBC method. Clin Chem. 2002; 48(9): 1565-70. doi: 10.1093/clinchem/48.9.1565.

[36] Islam R, Akter KM, Rahman A, Khanam NN, Al Azad S, Islam MR, Farjana M, Rahman MH, Badal MN, Ahmed S. The Serological Basis of the Correlation between Iron Deficiency Anemia and Thyroid Disorders in Women: A Community Based Study. J Pharm Res Int. 2021; 69-81. doi: 10.9734/jpri/2021/v33i19A31330.

[37] Srinivasan B, Finkelstein JL, O’Dell D, Erickson D, Mehta S. Rapid diagnostics for point-of-care quantification of soluble transferrin receptor. EBioMedicine. 2019; 1;42:504-10. doi:10.1016/j.ebiom.2019.03.017.

[38] Bohne S, Siggel R, Sachse S, Kiehntopf M, Bauer M, Straube E, Guntinas-Lichius O. Clinical significance and diagnostic usefulness of serologic markers for improvement of outcome of tonsillectomy in adults with chronic tonsillitis. J Negat Results Biomed. 2013;12(1):1-8. doi: 10.1186/1477-5751-12-11. [39] Akter KM, Tushi T, Mily SJ, Mohona RA, Anis S, Chakraborty AK, Tabassum E, Islam TU, Akhi OJ, Nishe IS, Laxy BN. RT-PCR Mediated Identification of SARS-CoV-2 patients from particular regions of Bangladesh and the multi-factorial analysis considering their pre and post infection health conditions. Biotechnol J Int. 2020; 43-56. doi: 10.9734/bji/2020/v24i630121. 
[40] Dey D, Paul PK, Al Azad S, Al Mazid MF, Khan AM, Sharif MA, Rahman MH. Molecular optimization, docking, and dynamic simulation profiling of selective aromatic phytochemical ligands in blocking the SARS-CoV-2 S protein attachment to ACE2 receptor: an in silico approach of targeted drug designing. J Adv Vet Anim Res. 2021; 8(1): 24. doi: 10.5455/javar.2021.h481.

[41] Sharif MA, Hossen MS, Shaikat MM, Masuk F, Haidary TI, Dey D, Paul PK, Azad SA, Mazid MF, Badal MN. Molecular Optimization, Docking and Dynamic Simulation Study of Selective Natural Aromatic Components to Block E2-CD81 Complex Formation in Predating Protease Inhibitor Resistant HCV Influx. Int J Pharm Res. 2021;13(2). doi: 10.31838/ijpr/2021.13.02.408.

[42] Al Azad S, Moazzem Hossain K, Rahman SM, Al Mazid MF, Barai P, Gazi MS. In ovo inoculation of duck embryos with different strains of Bacillus cereus to analyse their synergistic posthatch anti-allergic potentialities. Vet Med Sci. 2020; 6(4): 992-9. doi: 10.1002/vms3.279.

[43] Rashaduzzaman M, Kamrujjaman M, IslamMA, Ahmed S, Al Azad S. An experimental analysis of different point specific musculoskeletal pain among selected adolescent-club cricketers inDhaka city. Eur J Clin Exp Med. 2019; 17(4): 308-314. doi: 10.15584/ejcem.2019.4.4.

[44] Kmieć P, Sworczak KJE, Endocrinology C, Diabetes. Vitamin D in thyroid disorders. Exp Clin Endocrinol Diabetes. 2015;123:386-93. doi: 10.1055/s-0035-1554714.

[45] Muscogiuri G, Mitri J, Mathieu C, Badenhoop K, Tamer G, Orio F, et al. Mechanisms in endocrinology: vitamin D as a potential contributor in endocrine health and disease. Eur $\mathrm{J}$ Endocrinol. 2014; 171:R101-10. doi:10.1530/EJE-14-0158.

[46] Prietl B, Treiber G, Pieber TR, Amrein K. Vitamin D and immune function. Nutrients. 2013;5:250221. Doi: 10.3390/nu5072502.

[47] Chun RF, Liu PT, Modlin RL, Adams JS, Hewison M. Impact of vitamin D on immune function: lessons learned from genome-wide analysis. Front Physiol. 2014;5:151. doi: 10.3389/fphys.2014.00151.

[48] Stöcklin E, Eggersdorfer M. Vitamin D, an essential nutrient with versatile functions in nearly all organs. Int J Vitam Nutr Res. 2013; 83:92-100. doi: 10.1024/0300-9831/a000151.

[49] Mele C, Caputo M, Bisceglia A, Samà MT, Zavattaro M, Aimaretti G, et al. Immunomodulatory Effects of Vitamin D in Thyroid Diseases. Nutrients. 2020;12. Doi: 10.3390/nu12051444.

[50] Ahmed F, Khan MR, Shaheen N, Ahmed KMU, Hasan A, Chowdhury IA, et al. Anemia and iron deficiency in rural Bangladeshi pregnant women living in areas of high and low iron in ground water. Nutrition. 2018;51-52:46-52. doi: 10.1016/j.nut.2018.01.014. 
[51] Chen Y, Wan J, Xia H, Li Y, Xu Y, Lin H, et al. Total iron binding capacity (TIBC) is a potential biomarker of left ventricular remodelling for patients with iron deficiency anaemia. BMC Cardiovasc Disord. 2020;20:4. doi: 10.1186/s12872-019-01320-3.

[52] Harjantini U, Retno Dewi YL, Hanim D, Nurwati I. Correlation of dietary iron intake and serum iron with thyroid stimulating hormone (TSH) and free thyroxine (FT4) levels in adult hyperthyroid patients. J. Basic Clin. Physiol. Pharmacol. 2021;32:571-6. doi: 10.1515/jbcpp-2020-0483.

[53] Esan AJ. Hematological differences in newborn and aging: a review study. Hematol Transfus Int J. 2016;3(3):178-190. doi: 10.15406/htij.2016.03.00067.

[54] Kim D. The Role of Vitamin D in Thyroid Diseases. Int J Mol Sci. 2017;18. doi: 10.3390/ijms 18091949.

[55] Lee JA, Hwang JS, Hwang IT, Kim DH, Seo JH, Lim JS. Low vitamin D levels are associated with both iron deficiency and Anemia in children and adolescents. Pediatr Hematol Oncol. 2015;32:99-108. doi: 10.3109/08880018.2014.983623.

[56] Sim JJ, Lac PT, Liu IL, Meguerditchian SO, Kumar VA, Kujubu DA, et al. Vitamin D deficiency and Anemia: a cross-sectional study. Ann hematol. 2010;89:447-52. doi: 10.1007/s00277-009-0850-3.

[57] Blanco-Rojo R, Pérez-Granados AM, Toxqui L, Zazo P, de la Piedra C, Vaquero MP. Relationship between vitamin $\mathrm{D}$ deficiency, bone remodelling and iron status in iron-deficient young women consuming an iron-fortified food. Eur J Nutr. 2013; 52:695-703. doi: 10.1007/s00394-012-0375-8.

[58] Raveendran A, Shiji P, Rajini P, Al Qassabi FSJBMJ-IX. Iron deficiency anemia: an update. BMH Med J-ISSN 2348-392X 64 2019;6:116-30.

[59] Malczewska-Lenczowska J, Sitkowski D, Surała O, Orysiak J, Szczepańska B, Witek K. The Association between Iron and Vitamin D Status in Female Elite Athletes. Nutrients. 2018;10. doi: 10.3390/nu10020167.

[60] Kumari S, Swetha P, Krishnan RS, Nayak S, Singh S. The Association Between Ferritin and Vitamin D Levels in Premenopausal Fibroid Uterus Cases With Anemia. Cureus. 2021;13:e13392. doi: $10.7759 /$ cureus. 13392.

[61] Bacchetta J, Zaritsky JJ, Sea JL, Chun RF, Lisse TS, Zavala K, et al. Suppression of iron-regulatory hepcidin by vitamin D. J Am Soc Nephrol : JASN. 2014;25:564-72. doi: 10.1681/ASN.2013040355.

[62] Seong JM, Yoon YS, Lee KS, Bae NY, Gi MY, Yoon H. Gender difference in relationship between serum ferritin and 25-hydroxyvitamin D in Korean adults. PloS One. 2017;12:e0177722. doi: 10.1371/journal.pone.0177722.

[63] Iyer KM. Metabolic and Endocrine Disorders. General Principles of Orthopedics and Trauma: Springer Cham. 2019. p. 183-248. doi: 10.1007/978-3-030-15089-1_10. 
[64] Wang Y, Li H, Zheng M, Wu Y, Zeng T, Fu J, et al. Maternal vitamin D deficiency increases the risk of adverse neonatal outcomes in the Chinese population: A prospective cohort study. PloS One. 2018;13:e0195700. doi: 10.1371/journal.pone.0195700.

[65] Luster M, Duntas LH, Wartofsky L. The Thyroid and Its Diseases: Springer; 2019.

[66] Marei E, Elmaghraby D, Gad AA-MJEJoRS, Applications. Vitamin D Assessment In Iron Deficiency Anemic Pregnant Women and Their Newborns. Egypt J Rad Sci Applic. 2017;30:63-72. doi: 10.21608/EJRSA.2017.1179.1011. 